\title{
Pool boiling visualization on open microchannel surfaces
}

\author{
Robert Kaniowski ${ }^{1}$, and Robert Pastuszko ${ }^{1, *}$ \\ ${ }^{1}$ Kielce University of Technology, Department of Mechanics, al. 1000-lecia Państwa Polskiego 7, PL-25-314 Kielce, Poland
}

\begin{abstract}
The paper presents visualization investigations into pool boiling heat transfer for open minichannel surfaces. The experiments were carried out wih saturated water at atmospheric pressure. Parallel microchannels fabricated by machining were about $0.3 \mathrm{~mm}$ wide and 0.2 to $0.4 \mathrm{~mm}$ deep. Highspeed videos were used as an aid to understanding the heat transfer mechanism. The visualization study aimed at identifying nucleation sites of the departing bubbles and determining their diameters and frequency at various superheats.
\end{abstract}

\section{Introduction}

Knowledge about the conditions under which vapour bubbles form, the frequency of bubble detachment from a given nucleation site and their diameters at departure is the basis for the analysis of boiling mechanism. These quantities are determined, indirectly, with the use of high speed cameras.

Zhong et al. [1] studied pool boiling heat transfer with water as the working fluid. The inclination angles were $5^{\circ}, 30^{\circ}, 45^{\circ}, 60^{\circ}$ and $90^{\circ}$ (vertical), two structured surfaces with interconnected-grooves and cavities were investigated. The boiling process was photographed at various heat fluxes. The authors found that the structured surface which consisted of cavities as stable cavitycentric vaporization cores and interconnected grooves as the cooling water supply pathways provided significant heat transfer enhancement and increase in CHF.

In [2], the authors experimented with water and ethanol at atmospheric pressure. The surface under test was a cooper specimen with microchannels with a $\Omega$ cross-section. Visualization studies revealed nucleation, growth and departure behaviours in the reentrant cavities and also that at higher heat fluxes, the bubbles tend to coalesce.

The authors of [3] used liquid nitrogen in their experiments at atmospheric pressure. At low heat fluxes, the bubbles were isolated and interactive effects were negligible. At high heat fluxes close to $\mathrm{CHF}$, the bubbles interacted heavily and appeared in the form of a cluster with a neck-like structure. Periodical break-up of the neck led to shedding the upper part of the cluster. At intermediate heat fluxes, the bubbles interacted significantly and single bubbles were impossible to be seen - diameters and detachment frequencies of the bubbles could not be determined.

In [4], the authors used water at atmospheric pressure. The heated surface comprised two cooper specimens: a solid copper interconnected microchannel net and a porous interconnected microchannel net. Visualization of boiling was performed for both surface

\footnotetext{
* Corresponding author: tmprp@tu.kielce.pl
}

types focusing on the bubble growth rate and the influence of the heated surface in the vapour bubble diameter.

The Kielce University of technology has long been conducting visualization studies of boiling with water, ethanol, FC-72 and Novec -649 from various structured surfaces for both pool boiling and flow boiling [5-10].

\section{Experimental set-up}

The test setup for the visualization studies is shown in Fig. 1. The main stand module, Fig. 2 consists of the specimen being investigated (5) soldered to the cylindrical copper bar (7) and placed under the glass vessel (3) filled with the working fluid (4). A $1200 \mathrm{~W}$ electric cartridge heater, $19 \mathrm{~mm}$ in diameter and $130 \mathrm{~mm}$ in length, was installed into the bar. The investigations were conducted with distilled water at atmospheric pressure. The setup was designed to allows determining the temperature difference between the liquid and the heated surface, the heat flux and the diameter and frequency of departing bubbles. Prior to the measurements, the fluid was degassed through preliminary boiling for about 15 minutes.

The images of the bubbles at the moment of their nucleation, growth and departure were obtained using a PHOT MV-D1024-160-CL (Photonfocus) digital monochromatic camera with a resolution of $1024 \times 758$ pixels. The camera recorded the photos at a speed of 300 fps at a resolution of $480 \times 360$ pixels with mean error 2 fps.

An EX-FH20 (Casio) camera was used to record the images of the entire surface of the specimen at a resolution of $480 \times 360$ and the recording speed of 210 fps, with the mean error of 2 fps. Lighting was provided by a halogen lamp with light pipes (front light and back light).

The study was carried out on copper specimens with parallel grooves cut in them. Figure 3 and Table 1 show geometrical dimensions of the grooves. 


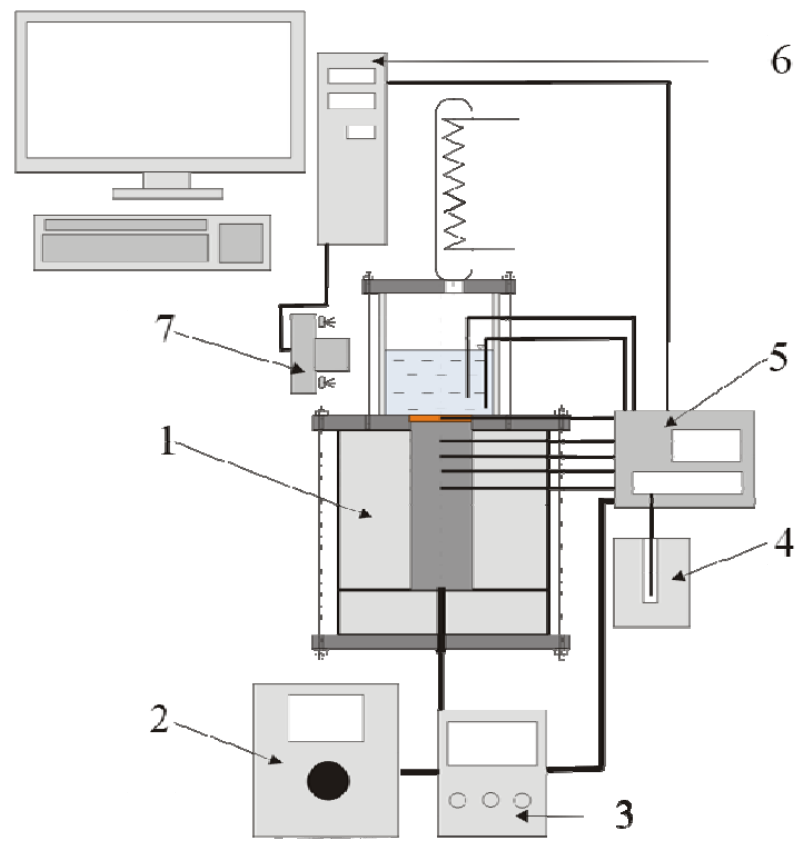

Fig. 1. Pool boiling visualization system: 1 - main module, $2-$ autotransformer, 3 - wattmeter, 4 - dry-well calibrator, 5 data logger, 6 - PC, 7 - high speed camera with lighting.

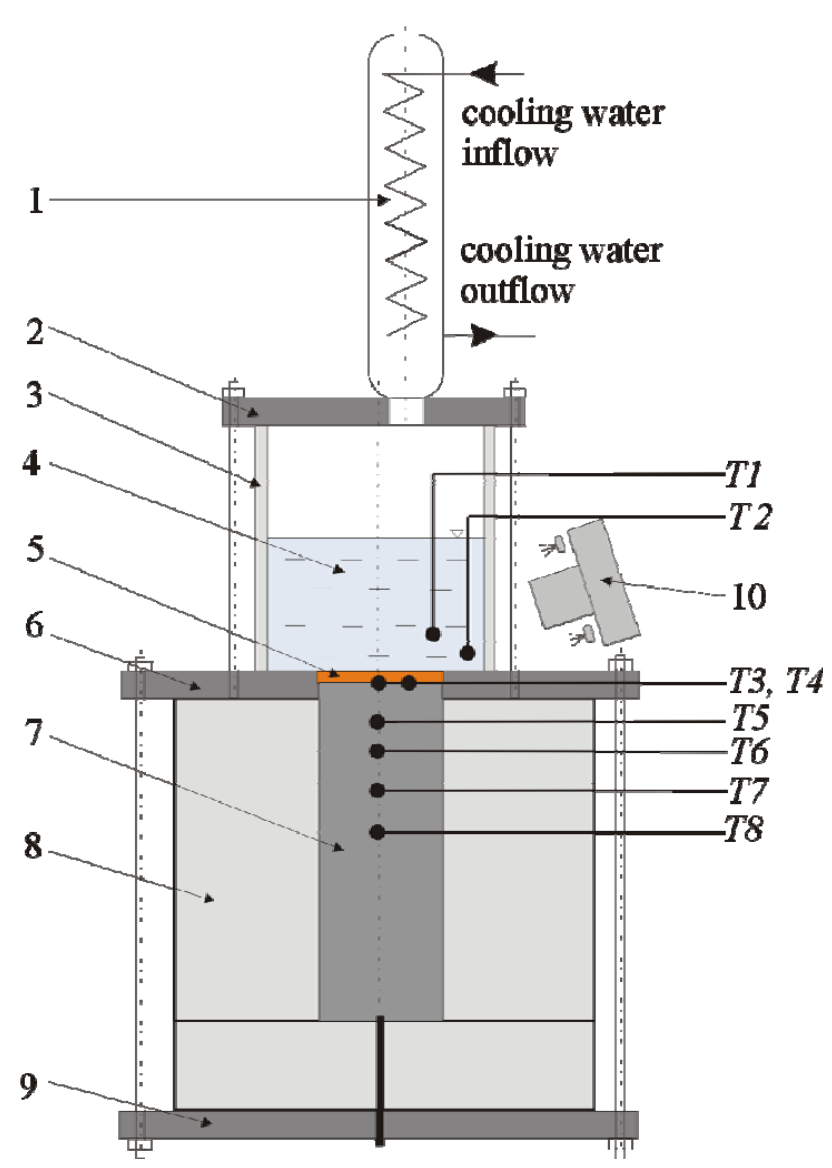

Fig. 2. Main module of pool boiling experimental stand: $1-$ condenser, 2 - top flange 3 - glass vessel, 4 - test fluid, 5 - test surface, 6 - teflon lid, 7 - copper bar with cartridge heater, 8 insulation, 9 - teflon base, 10 - high speed camera with lighting.
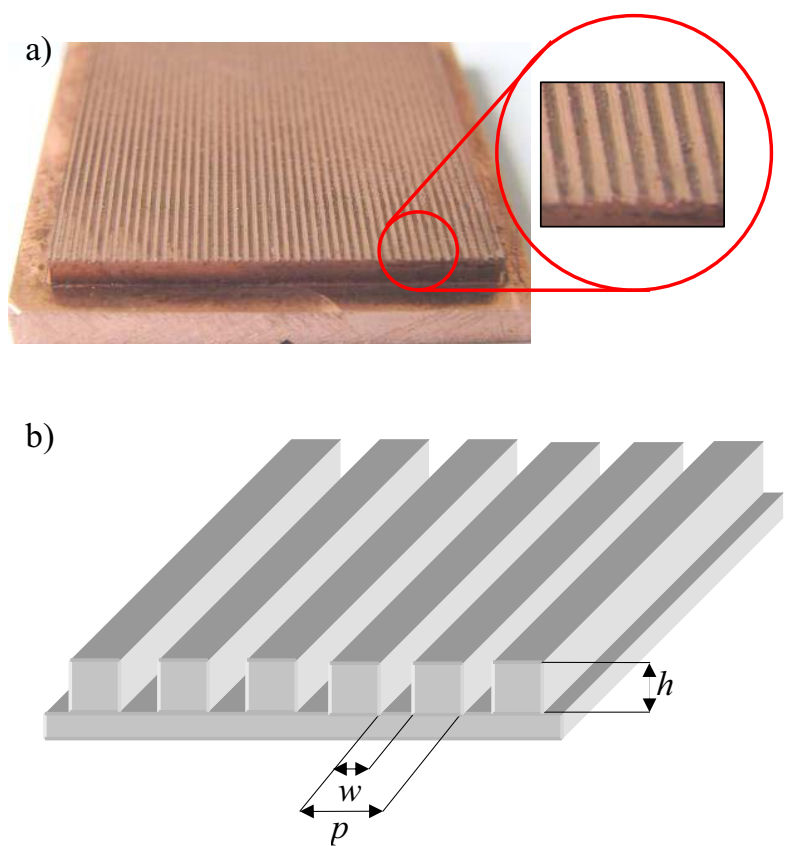

Fig. 3. Test surface: a) view of MC-0.3-0.2-0.6 specimen, b) dimension symbols.

Table 1. Surface codes and specifications.

\begin{tabular}{|c|c|c|c|}
\hline Specimen code & $\begin{array}{c}w \\
\mathrm{~mm}\end{array}$ & $\begin{array}{c}h \\
\mathrm{~mm}\end{array}$ & $\begin{array}{c}p \\
\mathrm{~mm}\end{array}$ \\
\hline $\mathrm{MC}-0.3-0.4-0.6$ & 0.3 & 0.4 & 0.6 \\
\hline $\mathrm{MC}-0.3-0.3-0.6$ & 0.3 & 0.3 & 0.6 \\
\hline $\mathrm{MC}-0.3-0.2-0.6$ & 0.3 & 0.2 & 0.6 \\
\hline
\end{tabular}

\section{Results}

Figure 4 includes typical images of boiling of the working fluid at increasing heat flux. The photographs were taken after temperatures on the heating bar and under the specimen stabilised at constant heat flux. Bubble diameters and nucleation site number grew along with increasing heat flux. At small superheats, $\Delta T<5.5$ $\mathrm{K}$, on surfaces MC-0.3-0.2-0.6 and MC-0.3-0.4-0.6 and at $\Delta T<3.5 \mathrm{~K}$ on MC-0.3-0.3-0.6, the vapour bubbles had regular spherical shapes. When $\Delta T \approx 6.0 \mathrm{~K}$ and $q \approx 57 \mathrm{~kW} / \mathrm{m}^{2}$ for the microchannels 0.2 and $0.4 \mathrm{~mm}$ deep and at $\Delta T \approx 3.5 \mathrm{~K}$ and $q<57 \mathrm{~kW} / \mathrm{m}^{2}$ for the surfaces with microchannels $0.3 \mathrm{~mm}$ deep, most bubbles had a form of a flattened sphere. Few bubbles coalesced because their diameters were larger than the distances between their formation sites. When the superheat was increased above $4.1 \mathrm{~K}$ and at $q>88 \mathrm{~kW} / \mathrm{m}^{2}$, most bubbles coalesced forming irregular, changing in time shapes, usually funnel-shaped from the lower part. At these vapour formations (bubble groups) the diameters and frequencies of departing bubbles became impossible to measure. 


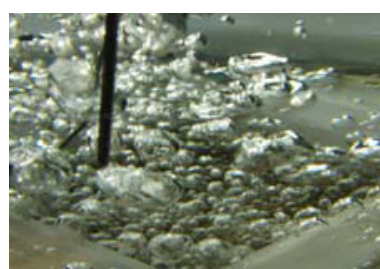

(a) $q=24.3 \mathrm{~kW} / \mathrm{m}^{2}$

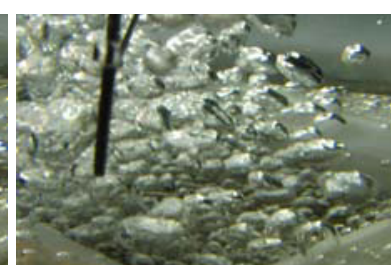

(b) $q=39.5 \mathrm{~kW} / \mathrm{m}^{2}$

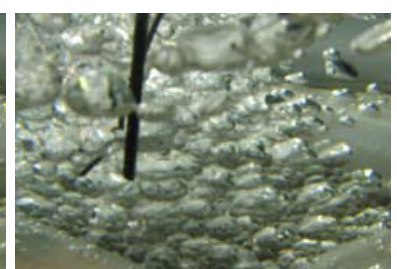

(c) $q=57.3 \mathrm{~kW} / \mathrm{m}^{2}$

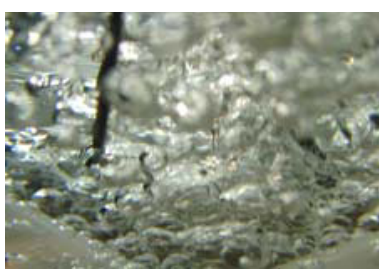

(d) $q=88.3 \mathrm{~kW} / \mathrm{m}^{2}$

Fig. 4. Visualization observations of pool boiling of water on the microchannel surface MC-0.3-0.3-0.6.

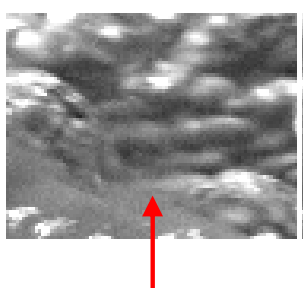

(a) bubble

nucleation

$t=0 \mathrm{~ms}$

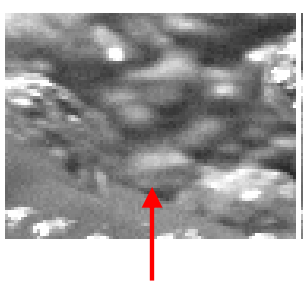

(b) bubble

growth

$t=3.3 \mathrm{~ms}$

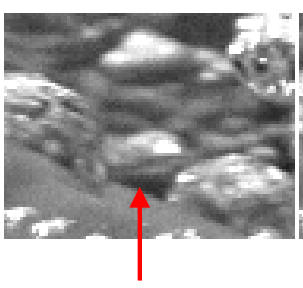

(c) bubble

growth

$t=6.6 \mathrm{~ms}$

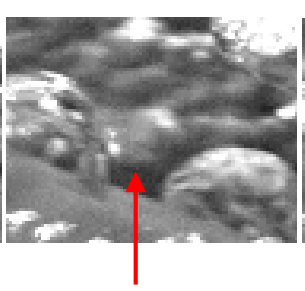

(d) bubble growth

$t=9.9 \mathrm{~ms}$

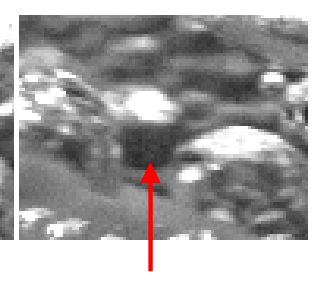

(e) bubble departure $t=13.2 \mathrm{~ms}$

Fig. 5. Successive bubble formations on MC-0.3-0.3-0.6 specimen at $q=24.3 \mathrm{~kW} / \mathrm{m}^{2}$, water.

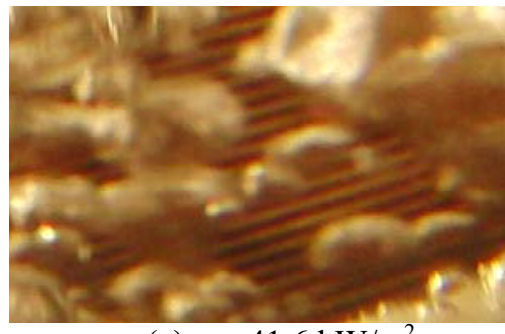

(a) $q=41.6 \mathrm{~kW} / \mathrm{m}^{2}$

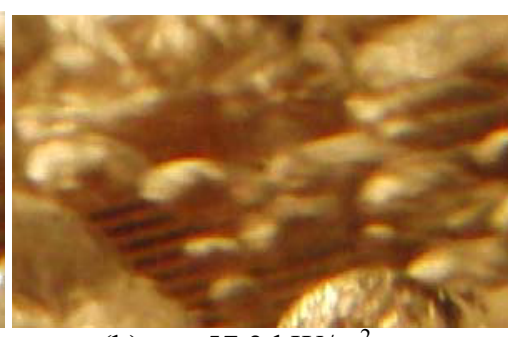

(b) $q=57.3 \mathrm{~kW} / \mathrm{m}^{2}$

Fig. 6. Vapour bubble generation, MC-0.3-0.4-0.6, water.

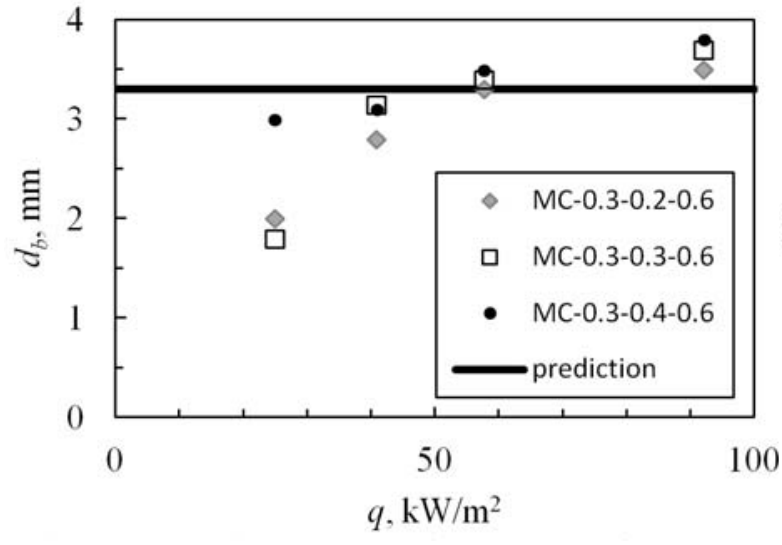

Fig. 7. Averaged departing bubble diameters for water.

Figure 5 shows an example of bubble nucleation at small superheats, $\Delta T<5.5 \mathrm{~K}$. After nucleation, the bubble grows up to the limiting value and detaches from the heated surface. Enlarged photographs of vapour forming on the specimen surface are shown in Fig. 6.

Bubble diameters and detachment frequencies were averaged from $8-10$ nucleation sites for a minimum of 30 consecutive vapour bubbles. The diameter was measured along two directions. The quantities were determined at a constant heat flux. Absolute error of the diameter measurement was 2 pixels, which gives $0.2 \mathrm{~mm}$ [8].

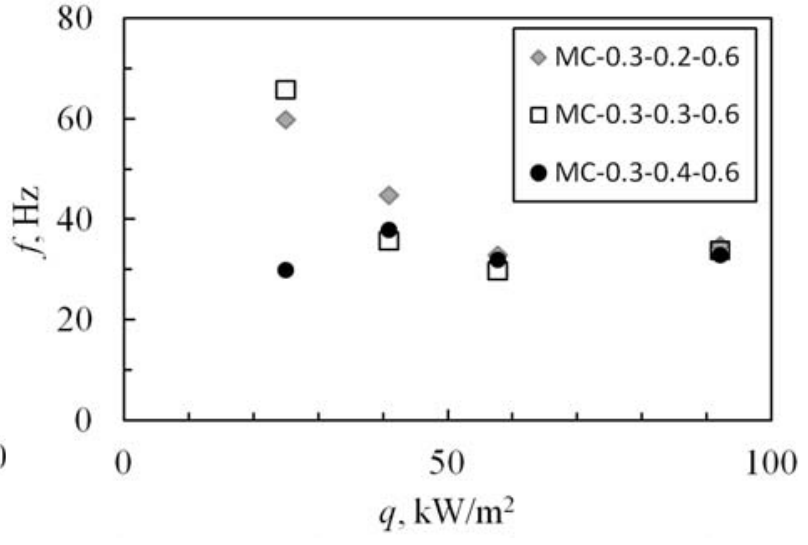

Fig. 8. Averaged departing bubble frequencies for water.

Figure 7 shows the experimental results for the influence of heat flux on departing bubble diameter and Fig. 8 shows the frequency of bubble detachment from the heated surface during the boiling of water relative to the heat flux. Theoretical values of departing bubble diameters were calculated according to the dependence [5]:

$$
d_{b}=\left(\frac{6 \sigma d_{h}}{g\left(\rho_{l}-\rho_{v}\right)}\right)^{0.33}
$$



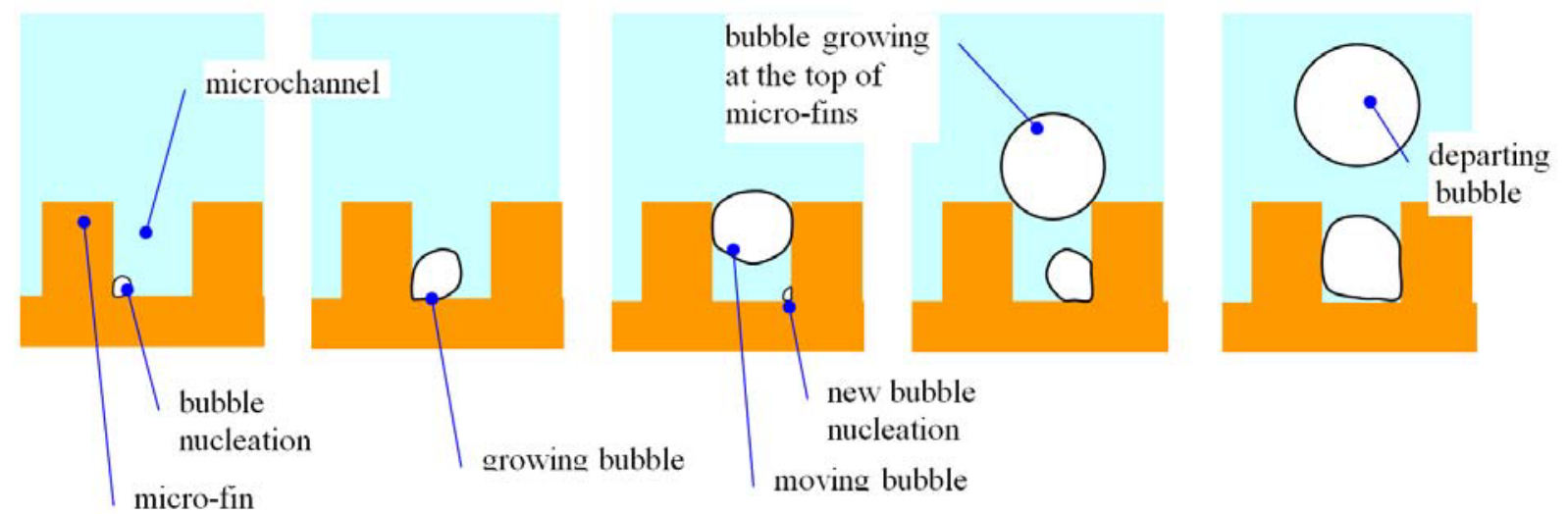

Fig. 9. Bubble growth in the microchannel space.

In addition, hydraulic diameter was assumed to be equal to the width of the microchannel, i.e., $d_{h}=w$.

At small heat fluxes $\left(q<40 \mathrm{~kW} / \mathrm{m}^{2}\right)$, bubble diameters are smaller than the calculated ones (Eq. 5) and detachment frequencies vary with surface type. At heat fluxes above $40 \mathrm{~kW} / \mathrm{m}^{2}$, averaged diameters are approximate in value to the predicted ones in equation 5 and the detachment frequencies stabilize at the level of $35-40 \mathrm{~Hz}$.

On the basis of the visualization studies carried out by the authors of this paper and the visualization reported for a similar surface by Cooke and Kandlikar [4], a possible scenario of bubble growth phases in a microchannel is shown in Fig. 9. Nucleation starts in the corner between the channel bottom and the vertical side wall. The bubble grows to fill the microchannel space. At the same time, a new bubble at the bottom of the microchannel increases in volume and pushed larger bubble upwards toward the microfin tips. During this motion, intensive heat transfer from the microfin surfaces to the vapour leads to an increase in pressure and volume of the bubble. Further expansion of the bubble at the microfin tips contributes to its detachment.

\section{Conclusions}

Visualization of boiling mechanism allows formulating the following conclusions:

- At low superheats, the bubbles between the heated surface and liquid are spherical in shape and do not coalesce. At higher superheats, the bubbles interact with each other intensively, forming flattened spherical shapes funnel-shaped at the bottom.

- A minor increase in bubble diameter was observed at the moment of detachment at increasing heat flux, along with a substantial rise in the frequency of bubble generation at low $q$.

- In the preliminary model of vapour bubble formation and growth, nucleation was assumed to take place at the corners at the bottom of the microchannel, and the growing bubble forces its way through the channel space between the microfins in the direction of their tips, where it departs.

\section{Nomenclature}

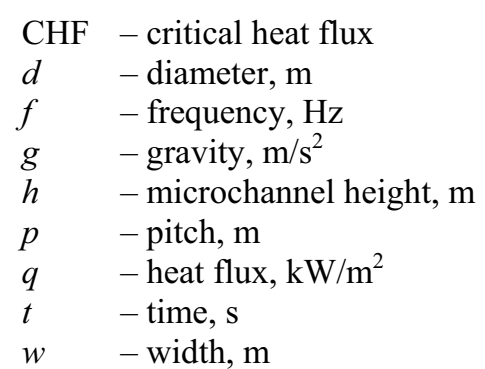

\section{Greek symbols}

$\Delta T$ - difference of temperature, $\mathrm{K}$

$\rho \quad-$ density, $\mathrm{kg} / \mathrm{m}^{3}$

$\sigma \quad-$ surface tension, $\mathrm{N} / \mathrm{m}$

\section{Subscripts}

$\begin{array}{ll}b & - \text { bubble } \\ h & - \text { hydraulic } \\ l & - \text { liquid } \\ v & \text { - vapour }\end{array}$

\section{References}

1. D. Zhong, J. Meng, Z. Li, Int. J. Therm. Sci., 108 (2016)

2. D. Deng, W. Wan, J. Feng, Q. Huang, Y. Qin, Y. Xie, App. Therm. Ing. 107, (2016)

3. X. Zhang, J. Chen, W. Xiong, T. Jin, Cryogenics, 72, (2015)

4. D. Cooke, S. G. Kandlikar, Int. J. Heat Mass Transfer, 55, (2012)

5. R. Pastuszko, Exp. Therm. Fluid Sci. 38, (2012)

6. R. Pastuszko, T. Wójcik, Exp. Therm. Fluid Sci. 63, (2015)

7. R. Pastuszko, R. Kaniowski, EPJ Web of Conferences, 25, 02019 (2012)

8. S. Hozejowska, R. Kaniowski, M. Poniewski, Exp. Therm. Fluid Sci. 78, (2016)

9. M. Piasecka, Int. J. Heat Mass Transfer 81, (2015)

10. M. Piasecka, B. Maciejewska, Exp. Therm. Fluid Sci.78, (2015) 